\title{
OBITUARY
}

\section{Brian B. Boycott}

\author{
December 10, 1924-April 22, 2000
}

This issue of Visual Neuroscience contains the last scientific contribution of Brian B. Boycott. In December 1999, Brian was just recovering from a serious operation in London, when I sent him an early draft of the paper. He returned the manuscript with many excellent suggestions for improvements and in the accompanying letter he wrote, "I think you are generous to include my name. I won't argue because when it comes out in 2000 it will be the 50th anniversary of my first published paper. This appeals to me." Unfortunately Brian did not live to see the publication of this paper and passed away on April 22, 2000.

Brian had an unusual career, starting in 1942 as an animal house technician in the National Institute for Medical Research. In the evenings he studied Zoology at Birbeck College, University of London. He was an assistant lecturer in the Department of Zoology, University College, London, from 1946 to 1947 and then moved to the Anatomy Department. There began his first "scientific period" in close association with John Z. Young on the brain and behavior of cephalopods - in particular, the memory mechanisms of the common octopus. Most of their work was done at the famous Stazione Zoologica in Naples, Italy. Brian's stories about life in post-WWII Naples were not only entertaining, but also good lessons on human behavior under difficult circumstances. Brian returned to University College in 1952 as a lecturer; he became a reader in 1962 and a professor in 1968.

During these years, Brian continued his work on the octopus brain, and even though teaching took an increasing proportion of his time, it was also a period of change in his research. Memory formation was still the focus of his interests, and together with Ray W. Guillery, around 1958, he began to study the structure and function of the hippocampus in reptiles and eventually other vertebrates. More than 30 years ago, the anatomical methods available to determine the connections in the brain involved making a lesion in the regions of interest and looking for degenerated products with the neurofibrillar silver staining methods. Neurofilaments became a structure that fascinated Brian for the rest of his life. Together with Guillery, he found that "synaptic rings" represent a torus of neurofilaments in the presynaptic terminal. Much later in the MRC Cell Biophysics Unit, the structure of neurofilaments became a major theme of his group. And even later, in cooperation with Leo Peichl, he perfected neurofibrillar staining methods of retinal wholemounts in order to study horizontal and alpha ganglion cells. Currently, when immunocytochemical methods have made selective staining so precise, one cannot imagine that Brian had to toil for hours to find the right composition of the water (the "agua gorda" of Ramón y Cajal) that would give optimal results with reduced silver or Golgi methods.



During the early 1960s, Brian became interested in the traces of memory formation in brain structures, and he was intrigued by the idea that the density of spines somehow reflects the activity of neurons. He wanted to study this problem by comparing the brains of hibernating animals, during sleep and awake periods. On sabbatical at the Biological Laboratories, Harvard in 1964, he shared the use of ground squirrels with John E. Dowling, who had started to look, using the electron microscopy, at the structure of the inner plexiform layer of the vertebrate retina. John took the retinae of the ground squirrels, whereas Brian was more interested in staining their brains with the Golgi method. What happened by chance became a merger of interests and talent. They started to work together on the mammalian retina with combined Golgi staining and electron microscopy. The outcome of that study is one of the highlights of neuroscience in the 20th century, the wiring diagram of the primate retina, published in 1966. Later Helga Kolb joined the team, and classical papers on flat and invaginating contacts in the outer plexiform layer as well as an analysis of the bipolaramacrine cell interactions in the inner plexiform layer resulted from these efforts. 
Brian was elected a Fellow of the Royal Society in 1971. In 1972, he moved to the Medical Research Council (MRC) Biophysics Unit at Kings College, London, as a Professor of Biology. In 1980, he succeeded M.H.F. Wilkins as Director of that Unit, with Dr. D. Reese as Associate Director. In the meantime, Brian had built up an excellent group of young people interested in the cellular and molecular biology of neurons (D. Bray, J. Brockes, D. Gilbert, and J. Scholes). Despite heavy administrative duties, Brian continued to be a productive researcher, and there was no doubt that he enjoyed it much more to look through a microscope than to participate in a Committee Meeting.

From 1972, Brian became engaged in a European Collaboration with L. Peichl, myself and our coworkers. He invited me to look at his most beautiful Golgi-stained wholemounts of the cat retina in 1972. In only 6 weeks, we performed a morphological classification of the ganglion cells of the cat retina. This work, together with the X/Y classification of Enroth-Cugell and Robson and the physiological studies of the Australian groups (Cleland, Dubin \& Levick; Hoffmann, Fukuda \& Stone), laid the groundwork for the concept of parallel processing in the mammalian retina. An image projected onto the retina is sampled by many different ganglion cells which transfer separate messages to the visual centers of the brain. This European Cooperation lasted for nearly 30 years. Brian visited Germany frequently: First when we worked together at the University of Konstanz, later at the Max-Planck-Institute in Tübingen and for the last 18 years at the Max-Planck-Institute for Brain Research in Frankfurt/M. His visits were always periods of intensive work, and the heated discussions about cell types at the microscope became legendary in the laboratory.

The working periods were interrupted by wonderful excursions to the countryside, to romantic old cities, to baroque churches and castles. Many evenings, exhausted from work, we ended up at the local pubs (Weinstube), drinking wine from the area and talking about everything except science. It was great fun to be together with Brian, for example, in conversations he could elucidate the similarities and general principles of flying buttresses of gothic churches, of the iron architecture of glass houses in botanical gardens and of the cytoskeleton of nerve cells. During this long collaboration we worked together on cell mosaics in the mammalian retina, which suggested a new definition of a "cell type". One cell type, the horizontal cells, of the mammalian retina had long captured the interest of Brian, from the early studies with John Dowling, Steve Fisher and Helga Kolb to his last paper published here. These cells were an intellectual nemesis "I do not understand what these cells are for and how they do their job." The paper on monkey horizontal cells in this issue of Visual Neuroscience co- authored by Brian contains an unexpected finding, suggesting that biplexiform ganglion cells are actually ectopic horizontal cells. Brian was extremely excited about this finding, because he always wanted to make the retina "simple" and was very reluctant to accept a novel observation at the microscope as a new cell type that neither Ramón y Cajal nor he himself had seen before! However, we are glad that most of his scientific contributions did not make the retina more simple, but instead raised new questions and opened new fields of research. This not only kept him busy throughout his life, but laid the groundwork for all of us who are interested in understanding the circuitry of the retina and of the visual system.

After retiring from the Directorship of the MRC Biophysics Unit at King's College, Brian joined as Professor Emeritus the Department of Anatomy of Guy's Hospital Medical School (University of London). He continued to be productive there and together with his outstanding technician John Hopkins, he carried out elaborate studies of the synapses made by bipolar cells of the monkey retina at the cone pedicle. It became clear that already at the first synapse of the retina, the cone pedicle, parallel processing starts, as the cone signal is fed into probably as many as ten different types of bipolar cells. In his new surrounding at Guy's Hospital Brian again made many friends, and the stimulating atmosphere there, with many young enthusiastic scientists, was a kind of elixir that kept him young. Everybody enjoyed discussing problems of neurobiology with him, in addition, he was a kind of a father figure giving advice about personal problems. When the Institute of Ophthalmology at the University of London offered him the opportunity to join the institute as an Emeritus, he was very pleased and became an active member of this outstanding institution. It is gratifying that his numerous important contributions to retinal circuitry were honored last spring by the Association for Research in Vision and Ophthalmology (ARVO) that awarded the Proctor Medal to Brian and myself.

We will miss him and will never forget him, our sympathy goes with his wife Marjorie and his son Antony. Most importantly, we will try to meet the high standard he has set. Last autumn Brian was invited by the Society for Neuroscience to contribute his recollections to their series of autobiographies. His autobiography will appear this autumn and will give much more insight into his life than this brief note can.

Frankfurt in May 2000

Heinz Wässle

Max-Planck-Institut für Hirnforschung 